\title{
Proposal of a dynamic numerical approach in predicting flashover critical voltage
}

\author{
Ali. A. Salem ${ }^{1}$, R. Abd-Rahman', M. S. Kamarudin ${ }^{3}$, H. Ahmad ${ }^{4}$, N.A.M. Jamail ${ }^{5}$, N.A. Othman ${ }^{6}$, \\ M.T. Ishak ${ }^{7}$, M.N.R. Baharom ${ }^{8}$, S. Al-Ameri' \\ 1,2,3,4,5,6,8,9 Faculty Electrical and Electronic Engineering, University Tun Hussein Onn Malaysia (UTHM), Malaysia \\ ${ }^{7}$ Faculty of Engineering, National Defence University of Malaysia (UPNM), Malaysia
}

\begin{tabular}{l}
\hline \hline Article Info \\
\hline Article history: \\
Received Dec 18, 2018 \\
Revised Jan 22, 2019 \\
Accepted Feb 23, 2019 \\
\hline Keywords: \\
Arc length \\
Conductivity \\
Flashover model \\
Outdoor insulator \\
Pollution layer \\
\hline
\end{tabular}

\begin{abstract}
Glass insulators, due to its diverse characteristics, were used widely around the world for high voltage transmission lines. Surfaces of the insulators are exposed to high electrical, mechanical, and thermal stresses over the period of service. Accumulation of contamination distort stresses distribution along the insulators that may lead to flashover under severe condition. In this paper, Obenaus pollution model has been adopted to propose a dynamic mathematical modelling to determine flashover critical voltage with regard to parameters such as pollution conductivity, arc length, and width of layer of contamination on the surface of glass insulator. In addition, laboratory experimental works have been carried out according to IEC60305 to validate the results from numerical approach, which indicate a good agreement.
\end{abstract}

Copyright (C) 2019 Institute of Advanced Engineering and Science. All rights reserved.

\section{Corresponding Author:}

Ali Ahmed Ali Salem,

Department of Electrical and Electronic Engineering,

University Tun Hussein Onn Malaysia,

86400 Parit Raja, Johor, Malaysia,

Email: en.alisalem@gmail.com

\section{INTRODUCTION}

High voltage electrical grid and outdoor power system equipments are constantly subjected to diverse types of climate, for example, snow and contaminants, that may lead to flashovers. Flashovers on insulators surface under polluted conditions are widely acknowledged. It is a highly complicated situation because of the interaction between important parameters such as electrical stress, climate and environemtal aspects as well as the insulator profile/structure $[1,2]$. Under the same pollution situations, the real challenge is to propose insulators design with the greatest reliability and performance. Developing accurate models to predict the flashover at the polluted layer on the insulators and understanding the extend of the discharge has been the concern of numerous studies [3-5].

Numerical approach and modelling of pollution flashover can be a good solution to minimize experimental tests on the real insulators and experimental investigation on site. Several research studies have produced comparative numerical models addressing the flashover phenomenon $[3,5]$. In order to understand accurately propagation and growth of pollution flashover, dynamic aspects related to the electrical and environmental criterias shall be considered. Flashover models indicate the greatest probability of flashover occurance on polluted insulators [6]. The model can be use to predict flashover voltage and also to determine several major parameters, such as discharge time, velocity, and leakage current (LC).

In this research work, an alternative mathematical models is proposed to accurately predict flashover voltage at critical sites. In addition, the development of electric flashovers on pollution insulator surfaces as a function with increase the polluted region on the insulator surface $\mathrm{w}$, discharge distance $(\mathrm{x})$ and conductivity of pollution layer, $\sigma$ were also considered. Experimental results on pin-cup insulators under polluted 
conditions were compared to the results obtained using the proposed mathematical model for flashover prediction have shown a good aggrement.

\section{POLLUTION INSULATOR FLASHOVER PHENOMENON}

Various pollutants, such as dust, salt, and ice, cover the high voltage outdoor insulators, depending on wind direction, temperature, and humidity. Wet pollution is known to be the more serious type associated with a significant probability of flashover on insulator surfaces. Pollution flashover occur in stages as follow:

- the formation of pollution on the insulator surface decreases the leakage distance.

- presence of a wet layer caused by several factors, such humidity and rain on the pollution layer, causes the increase in surface conductivity.

- a formation of the dry band caused by the lc warming influences and increases the voltage, finally resulting in a flashover.

Based on laboratory tests and field experience, it was noted that flashover in insulators covered with a heavy pollution layer was not an immediate phenomenon, but results from a process involving pollution and discharges, comprised three stages, as illustrated in Figure 1 [2].

The First stage - Pollution accretion on insulators is non-uniform, as several regions on the insulators are not polluted. Such non-pollution zones are referred to as dry bands. This is due to the heating effect of the leakage current, partial arc activity, and increase in air temperature. It is generally agreed that the water film on the surface of the pollution layer is responsible for the breakdown or flashover that occurs. The increased voltage usually crosses the dry band because of conductive water on the pollution layer. The corona discharge starts mainly when there is a high electric field across the dry bands, and luminous branched filaments from the arc than appear, which develops from the root (stem), as shown in Figure 1(a).

The Second stage - The corona leads to the creation of partial arcs in the dry band regions causing a significant increase in LC. These luminous branched filaments develop to become a channel. The other properties of accumulated pollution over the insulator will modify over time due to the temperature and current leakage, as shown in Figure 1(b).

The Third stage - At this stage, the arc develops differently. One of two things occur, either the arcs die out or the arcs are propagated along the pollution layer on an insulator surface to become white arcs that occur according to a certain length from a white arc (around sixty percent of the length of the insulator). This depends on the conductivity and length of the contaminated region and finally, the flashover is complete along the insulator, as shown in Figure 1(c).
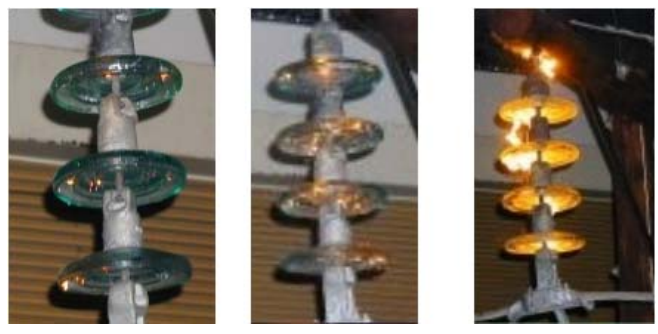

Figure 1. Process of flashover on polluted insulator

\section{CONCEPT OF THE MODEL}

One of the first models of flashover on polluted insulator surfaces was introduced by Obenaus [7]. Thus far, the most analytic models proposed by researchers since then have depended on the known design, in which a contaminated insulator was modelled by an electrical equivalent circuit consisting of an electrical resistance with an arc in series.

Where the dry band resistor was in series with the wet region resistor of an insulator, a contaminated surface was assumed. In this model, the arc channel was equivalented as a cylinder with a radius $r$ and length 1. It was also transferred to an RLC electrical circle, as shown in Figure 2.

The salient features of this model are briefly represented here. Figure 3 illustrates a flowchart of the mechanism model comprising the geometry of the insulator, characteristics of the contaminated layer, applied voltage, and some values of the initial reading used as the input data. The flashover discharge time was divided into steps $d t$ (below the time constant for an arc) from $t$ equals zero. From this, an estimated voltage of the arc was made, which must be high enough to obtain an arc that exceeds the first length for an

Proposal of a dynamic numerical approach in predicting flashover critical voltage (Ali. A. Salem) 
arc. When the prevalent criterion is met based on Hesketh's $d P_{a} / d x>0$, where $P_{a}$ is the arc power supply from the source of the power), the arc will start to develop. It is agreed that the propagation of the arc will be at that voltage. The internal variables (radius, velocity, etc.), as well as the remaining pollution layer's resistance, are then determined[8]. The determination of electrical parameters demands the immediate unbridged contaminated layer resistance, which is determined from the insulator geometry; thus, illustrating the effect of the flashover process. The voltage $U s(t)$, in the AC voltage form, was calculated at each time based on the same hypothesis as for the static modelling, which determined the voltage for the flashover, i.e. at the maximum value of voltage Us during a very short time, a flashover will occur. At each time $d t$, the critical situation for continued growth of the flashover were tested and, if it was favorable, the flashover would continue forward to the final leap step.

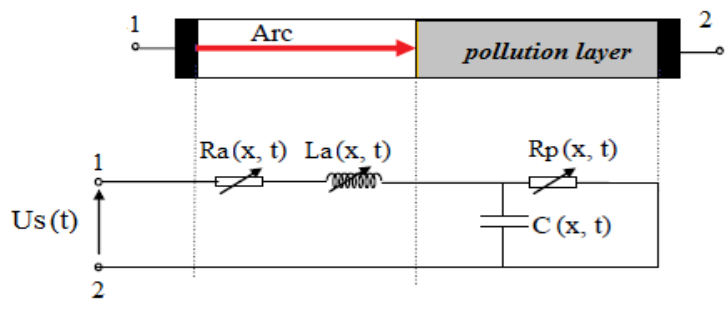

Figure 2. Modelling propagating flashover on a contaminated surface and Electrical equivalent RLC circuit

Otherwise, the arc will die-out, and a discharge would not occur. Then, a new step is repeated by increasing the applied voltage. The computing is re-run again by initializing the input parameters. When the arc length is equal to more than half the insulator length $L f$, the discharge would occur. Under alternating voltage, this occurs at the top value of the last quarter of the period cycle T/4 and consequently, velocity is modified to obtain all discharges at the same time. Thus, if the critical value is more than the surface conductivity, it is considered that the arc length is similar and any variation in the current is a result of the variation in the conductivity at the wet layer surface, as well as the resistance of the arc [9]. Then, using the determined value of FOV, the data in the last phase would be determined by repeating the simulation. At each $\Delta t$, the length of the arc and its resistance was initialized. If the criterion is not matched, the flashover would not occur. In this case, a new step increased the voltage Us. The computation was re-run by setting the input data as shown in flow chart in Figure 3.

\section{THE TESTS AND PROCEDURE}

Before the start of the descriptive experiment, the essential parameters that influenced the flashover voltage (FOV) were explained as follows:

The geometry of the insulator (i.e. diameter and length of arcing). The shorter the arcing distance, the smaller the flashover voltage; also, with a shorter diameter, the flashover voltage is at a maximum [10];

- A wet layer conductivity and pre-pollution;

- Properties of applied voltage (form and polarity);

- Environmental, temperature, atmosphere, stress and moisture;

- Type and nature of contaminants deposited (hard or soft rime, and water), with a lower density of pollution leading to higher flashover voltage;

- A uniform and non-uniform contamination layer surface

- Presence of dry bands: pollution deposits with lesser dry bands have lower flashover voltage [11];

Wet-pollution, which is the most dangerous type of pollution that creates flashovers, was used in the experiments carried out in this study. To achieve pollution, cold powder and salty water were used. To ensure prepared water for each experiment, the conductivity of water was measured by mixing sodium chloride $\mathrm{NaCl}$ (salt) and water [10].

The thickness of the pollution layer on the insulator was then determined. Wet-pollution was deposited on the insulator with a normal temperature of $25^{\circ} \mathrm{C}$. Figure 4 shows the experimental insulator used that consisted of an IEC standard $146 \mathrm{~mm}$ by $255 \mathrm{~mm}$ cap and pin glass insulator discs, one clean and one polluted.

Int J Pow Elec \& Dri Syst, Vol. 10, No. 2, June 2019 : 602 - 610 


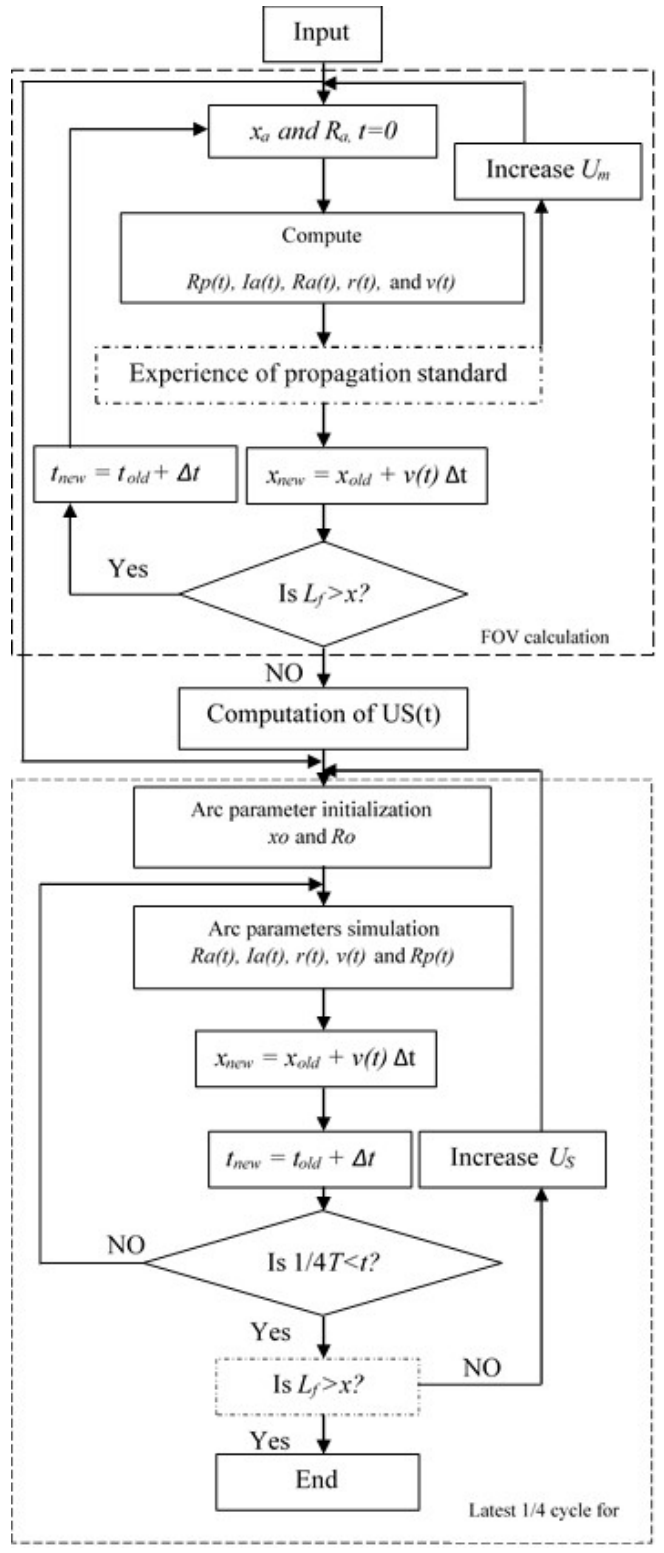

Figure 3. The model flow chart
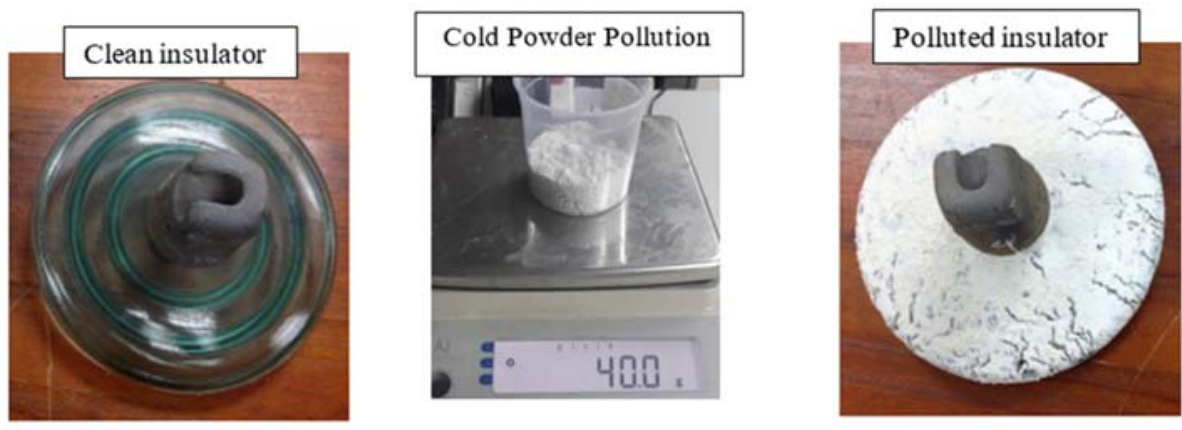

Figure 4. Glass insulator and pollution 
Experiments have validated on 4 IEC standard insulator units, the dimensions of insulator used is illustrated in Table 1.

Table 1. Geometrics of insulators used

\begin{tabular}{ccccc}
\hline & $\begin{array}{c}\text { Shed } \\
\text { diameter } \\
\mathrm{mm}\end{array}$ & $\begin{array}{c}\text { Shed } \\
\text { spacing } \\
\mathrm{mm}\end{array}$ & $\begin{array}{c}\text { Leakage } \\
\text { distance } \\
\mathrm{mm} / \text { unit }\end{array}$ & $\begin{array}{c}\text { Arcing } \\
\text { Distance } \\
\text { for 4 units } \\
\mathrm{mm}\end{array}$ \\
\hline 255 & 146 & 320 & 584 \\
\hline
\end{tabular}

A test setup comprising of a high voltage single transformer of $220 \mathrm{kV}$, capacitive divider for measure apply voltage, control panel, and data collect systems is shown in Figure 5. The transformer empowers the insulators with voltage. Parameters measuring system, which provides the factors effect on the Leakage Current such as the time changes, peak value, and mean value, includes an advanced oscilloscope and a $10 \mathrm{k} \Omega$ resistor divider for measuring LC under pollution and clean insulator. Leakage current measurements were carried out by applying voltage of $\left(20 /(3)^{0.5}\right)=11 \mathrm{kV} \mathrm{RMS} \mathrm{approxmatlly.}$

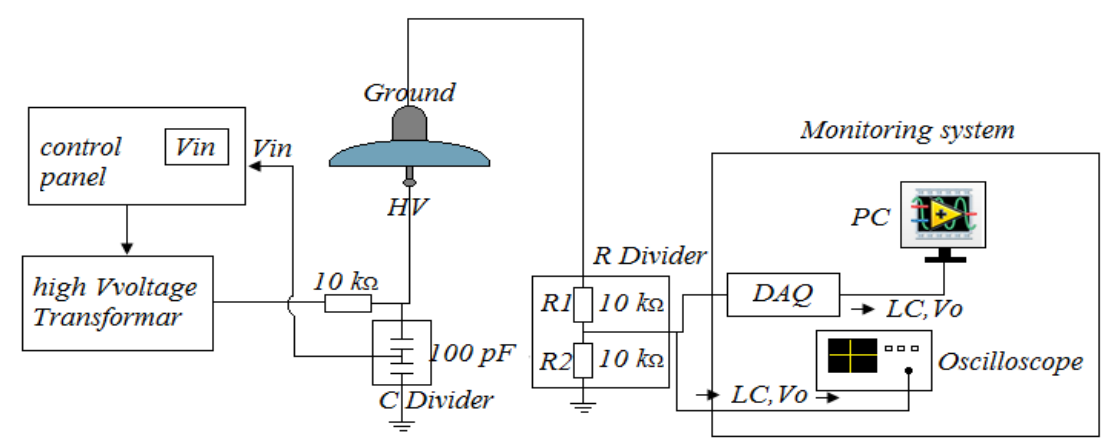

(a)
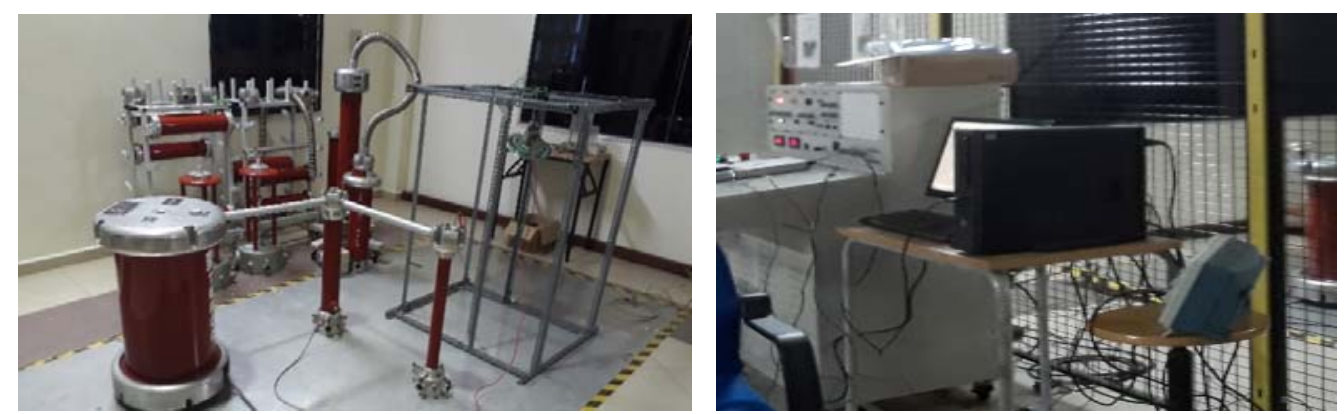

(b)

Figure 5. (a) HVAC circuit testing on outdoor insulator (b) Experimental test setup and arrangement and data acquisition system

\section{RESULTS AND ANALYSIS}

\subsection{Influence of insulator diameter}

This study is suitable for very heavy pollution cases on insulators, which are usually affected by dust or snow [12], [13]. The width (d) was commensurate to the insulator diameter. However, it is practically impossible to obtain such insulators. The contamination layers often accumulate on the windward regions of the insulators. Therefore, the simulation had used an experimental model as shown in Figure 6[11]. 


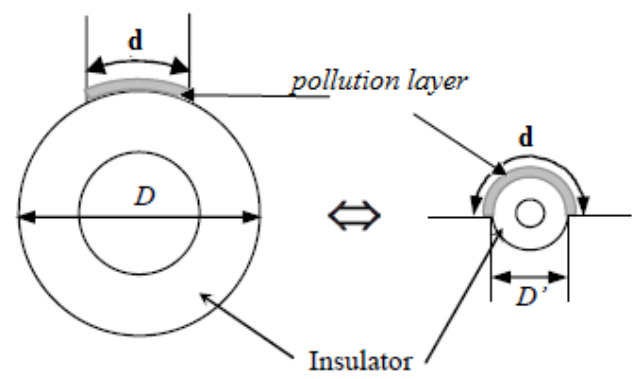

Figure 6. Simulation of the insulator diameter

as:

The contamination layer was estimated as a half cylinder with a width (d) over the insulator given

$$
d=\frac{\pi(D+2 w)}{2}
$$

where $\mathrm{D}$ is the diameter of the insulator and $\mathrm{w}$ is the contamination layer thickness.

While the equivalent diameter of insulator $D^{\prime}$ is given by:

$$
D^{\prime}=\frac{2 d}{\pi}-2 w
$$

the insulator diameter influence was computed with different widths of the pollution layer covering the insulator surface. A pollution layer thickness (w) of $1.5 \mathrm{~mm}$ and widths (d) of $4 \mathrm{~cm}, 9.4 \mathrm{~cm}, 14 \mathrm{~cm}$, and $28 \mathrm{~cm}$ respectively was selected for testing.

The results shown in figure 8 indicate that any increase in the width of the pollution layer (d) on the insulator would see adecrease in critical voltage (Vc). In addition, there was a good agreement between simulation and experiment results, as shown in Figure 7.

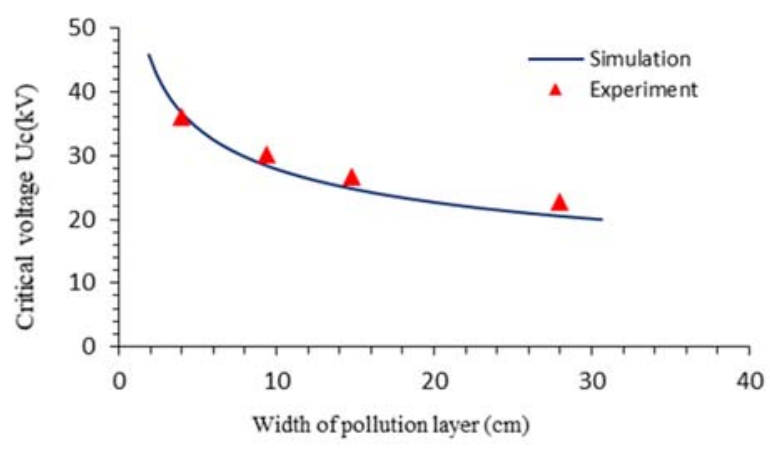

Figure 7. Critical voltage Vc as a function with Width of pollution layer for $\sigma=80 \mu \mathrm{S} / \mathrm{cm}$ and w $=1.5 \mathrm{~cm}$.

\subsection{Length of arc effect}

Critical voltage Vc is proportional to the length of arc L and number of insulator units increasing and decreasing. Figure 8 shows the critical voltage as a function with arc length for different leakage distance of insulator. Comparisons of the experimental results using one to four IEC60305 standard glass insulator units uniformly covered with wet contamination layer with critical flashover voltage simulated by the model are shown in Figure 8. The thickness of the pollution deposited on the insulator was about $1 \mathrm{~mm}$ for all the tests. 


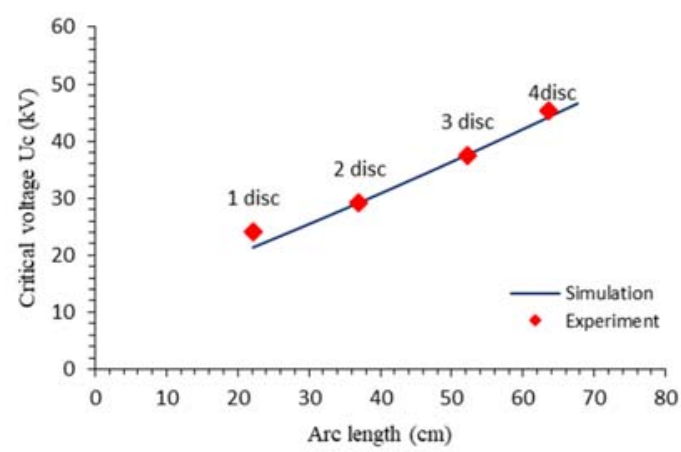

Figure 8. Critical voltage Vc as a function with arc length for $\sigma=80 \mu \mathrm{S} / \mathrm{cm}$ and $\mathrm{w}=1.5 \mathrm{~cm}$.

\subsection{Conductivity of wet-pollution layer effect}

Based on field investigations and laboratory experiments, it was found that wet-contamination layer conductivity has a considerable influence on the flashover voltage of insulators. Critical voltage was found to decrease as the contamination layer conductivity increased. The model outputs were also compared to laboratory results, acquired from a string of 4 units of IEC60305 standard glass insulators, where various water conductivities were tested as show in Figure 9. These results show that there is a good degree of agreement between the critical voltage calculated from the computation and the laboratory test results. The FOV had reduced with increasing conductivity of the pollution layer with minor errors.

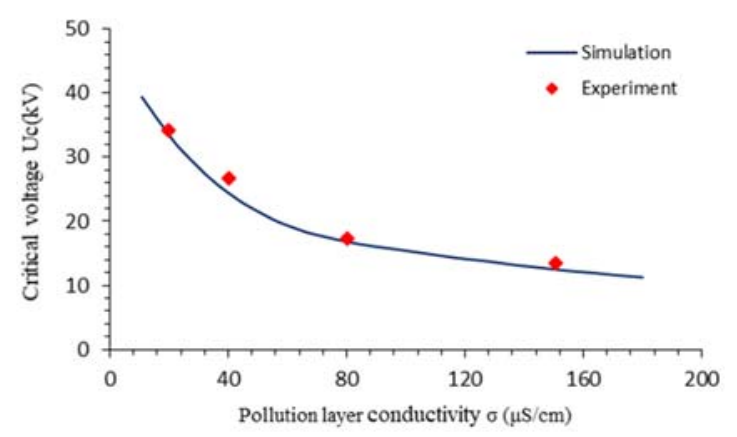

Figure 9. Critical voltage (Vc) as a function of pollution layer conductivity for $\mathrm{w}=1.5 \mathrm{~cm}$.

Based on the results, it was observed that there was good convention between the calculated results for the flashover voltage and those found experimentally. Arcing events are so difficult that many facilitating assumptions must be produced to obtain numerical modelling in an easier way.

\section{CONCLUSION}

In this study, a dynamic model was applied to investigate the effects of some parameters on the flashover voltage of polluted insulators. The suggested numerical model affected the sequential spread of the arc. The model inputs were the geometry of the insulator, pollution layer properties (a), applied voltage and some essential values. The outcome of the mathematical model was validated against the experimental model using pollution covered IEC60305 standard glass insulators, taking to account different lengths of the arc and diameters as well as different wet pollution layer conductivity. The experimental results closely resembled the results from the model and could forecast the flashover voltage (FOV) under AC voltage with agreeable accuracy.

Int J Pow Elec \& Dri Syst, Vol. 10, No. 2, June 2019: $602-610$ 


\section{ACKNOWLEDGEMENTS}

The authors would like to thank University Tun Hussein Onn Malaysia and the office for Research, Innovation, Commercialization, and consultancy Management (ORICC) for funding this research under the postgraduate Research Grant (GPPS), VOT \#U711.

\section{REFERENCES}

[1] F. A. M. Rizk, "Mathematical models for pollution flashover", Electra, vol. 78, pp. 71-103, 1981.

[2] A. Haddad, M. S. Kamarudin, and M. F. M. Yousof, "Dynamic modelling of polluted outdoor insulator under wet weather conditions," pp. 610-614, 2016.

[3] Ali. A. Salem; R. Abd Rahman; M. S. Kamarudin; N. A. Othman, "Factors and models of pollution flashover on high voltage outdoor insulators: Review" 2017 IEEE Conference on Energy Conversion (CENCON). pp. 241-246, 2017.

[4] A. P. and R. A.-R. M. S. Kamarudin, N. H. Radzi, "Simulation of electric field properties for air breakdown using COMSOL multiphysics", IET Conferences, pp. 1-5, 2016.

[5] R. Sundararajan and R. S. Gorur, "Dynamic arc modeling of pollution flashover of insulators under DC voltage", IEEE Trans. Electr. Insul, vol. 28, pp. 209-218, 1993.

[6] Ali. A. Salem, "A review of the dynamic modelling of pollution flashover on high voltage outdoor insulators,” J. Phys. Conf. Ser., vol. 1049, 2018.

[7] F. Obenaus, "Die überschlagspannung verschmutzter isolatoren", ETZ, Vol. 56, pp. 369-79, 1935.

[8] N. Dhahbi-Megriche and A. Béroual, "Flashover dynamic model of polluted insulators under ac voltage", IEEE Trans. Dielectr. Electr. Insul, Vol. 7, pp 283-9, 2000

[9] M. Marzinotto, J.-M. George, S. Prat, G. Lavecchia, M. R. Guarniere, A. Posati and M. Rebolini, " DC-toughened glass insulators pre-coated with RTV silicone rubber - field returns from aged samples installed on HVDC lines", IEEE Int'l. Conf. Solid Dielectr. (ICSD), Bologna, Italy, pp. 170-173, 2013.

[10] I. Gutman, J. Shamsujjoha, C. Lumb, J.-M. George, and S. Roude, "Investigation of rapid flashover solid layer pollution testing as an alternative to current standard methods", IEEE Int'l. Sympos. Electr. Insul. (ISEI), pp. 73-77, 2012.

[11] M. Farzaneh, J. Zhang and C. Volat, "Effect of insulator diameter on AC flashover voltage of an ice-covered insulator string", IEEE Trans. Elec. Insul., Vol. 13, pp. 264 - 271, 2006.

[12] J. Li, Z. Guan, L. Wang and H. Yang, "An experimental study of ac arc propagation over a contaminated surface", IEEE Trans. Dielectr. Electr. Insul., Vol. 19, pp. 1360-1368, 2012.

[13] N.A. Othman , M.A.M. Piah , Z. Adzis "Contamination effects on charge distribution measurement of high voltage glass insulator string"MEASUREMENT, Vol 7, 34, ISSN:0263-2241,2017.

\section{BIOGRAPHIES OF AUTHORS}

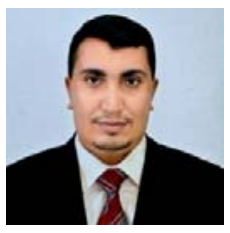

Ali Ahmed Ali Salem (Ali. A. Salem) was born in Sana'a, Yemen on March 1, 1985. He received M.Eng. in Electrical Power Engineering from Universiti Tun Hussein Onn Malaysia (UTHM) from 2014 to 2016. Currently he is Pursuing Ph.D. degree at High Voltage in Faculty of Electrical Engineering, UTHM. His research interest includes the dynamic arc modelling of pollution flashover on high voltage outdoor insulators.

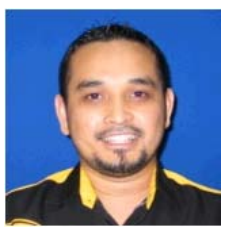

R. Abd Rahman was born in Kedah, Malaysia in 1984. He received the M.Eng. degree in electrical and electronic engineering from Cardiff University, UK in 2008. After his graduation, he joined Universiti Tun Hussein Onn Malaysia (UTHM) as an academic staff and research fellow. In 2008, he came back to Cardiff as a PhD candidate within the High Voltage and Energy Systems group and received his phD in 2012. Currently, he is a lecturer at University of Tun Hussein Onn Malaysia (UTHM), Batu Pahat, Malaysia.

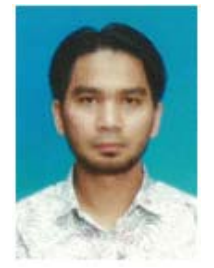

M. S. Kamarudin obtained his B.Eng. and M.Eng. Degrees in Electrical Engineering (Power) from Universiti Teknologi Malaysia (UTM) in 2003 and 2005, respectively, and a Ph.D. in High Voltage Engineering from Cardiff University, UK, in 2014. Currently, he is a senior lecturer in the Faculty of Electrical \& Electronic Engineering at Universiti Tun Hussein Onn Malaysia (UTHM). His research interests include gas discharges, high voltage surge arresters, and dielectrics and electrical insulation system. He is registered with the Board of Engineers Malaysia (BEM). He is also currently a member of IEEE and a graduate member of Institution of Engineers, Malaysia (IEM) 

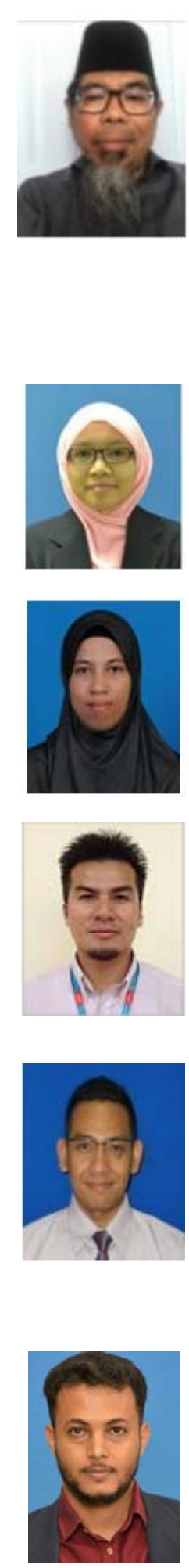

Hussein Ahmad was born in 1953 and graduated with BSc (Electrical and Electronic Engineering) and MSc (Electrical Power Engineering) from University of Strathclyde, Glasgow in 1977 and 1981 respectively. Subsequently received his $\mathrm{PhD}$ in high voltage engineering in 1986 from UMIST of University of Manchester.He was a contract professor at the University of Tun Hussein Onn Malaysia (UTHM), Batu Pahat, Malaysia in the Research Center of Applied Electromagnetics in the Faculty of Electrical and Electronic Engineering, UTHM. He was the former Chairman and Head of Power Engineering Chapter, IEEE Malaysia Chapter. His last position in UTM before retirement in 2011 was Director of Institute of High Voltage and High Current (IVAT) and professor of the Faculty of Electrical Engineering, UTM, Skudai. His research interest is the area earthing, bonding, lightning protection, insulation performance and renewable energy using lightning. His is also the Director of Dynamic Electrical and Lightning Earthing Solution enterprise (DELES). Currently he is an Adjunct Professor at IVAT, UTM (2018-2020)

Nor Akmal Mohd Jamail is a lecturer of Universiti Tun Hussein Onn Malaysia since 2008. She received the Bachelor degree in Electrical Engineering from Universiti Teknologi Malaysia in 2005, M.Eng in Power System from Universiti Tun Hussein Onn Malaysia in 2007 and Ph.D. in High Voltage Engineering from Universiti Teknologi Malaysia, in 2015. Her research interests include condition monitoring of polymer nanocomposite insulation for HV purpose, dielectrics and electrical insulation. She is registered with the Board of Engineers Malaysia (BEM).

Nordiana Azlin Othman was born in Johor, Malaysia on January 19, 1986. She received Diploma in Electrical Communication and B.Eng in Electrical Engineering from Universiti Teknologi Malaysia (UTM) respectively in 2007 and 2010. She completed her PhD in Space Charge Distirbution at Institute of High Voltage and High Current (IVAT) in Faculty of Electrical Engineering, UTM. Her research interest includes the detection and diagnostics of partial discharge and space charge in insulation for condition monitoring.

Mohd Taufiq Ishak received the B. Eng degree in Electrical Engineering (2002) from Universiti Tenaga Nasional in Malaysia and M. Eng. in Electrical Engineering (2004) from UMIST, UK. He received the $\mathrm{PhD}$ degree in Electrical Power Engineering from University of Manchester, UK in 2010. Currently he is a Senior Lecturer in the Department of Electrical and Electronic Engineering, Universiti Pertahanan Nasional Malaysia. His research interests are high voltage, power transformer, asset management, lifetime prediction, renewable energy, conditioning monitoring and smart grid.

Md Nor Ramdon Bin Baharom was born in Kuala Lumpur, Malaysia on August 1978. He received the B.E. degree in Electrical and Electronic Engineering from School of Computing, Creative Technologies \& Engineering, Leeds Metropolitan University, United Kingdom in 2004. He received the Ph.D. degree from Electrical Energy and Power Systems Group of the School of Electrical and Electronic Engineering at the University of Manchester in 2010. He is currently working as a lecturer in Department of Power Electrical Engineering of the Faculty of Electrical and Electronic Engineering, Universiti Tun Hussein Onn Malaysia (UTHM), Malaysia. His major research interests include high-voltage insulations, overhead-line design, lightning structure protection, electrical environmental interference impact, composite insulators and flashover of contaminated insulators.

Salem Mgammal Awadh Nasser Al-Ameri received B.Eng. in Mechatronics Engineering from Asia Pacific University (APU) in 2012. He received M.Eng. in Electrical Power from Universiti Tun Hussein Onn Malaysia (UTHM) from 2014 to 2016. Currently he is pursuing Ph.D. Degree in Universiti Tun Hussein Onn Malaysia. His research is on transformer condition monitoring using FRA. 